\title{
Serum myokine (myostatin and IGF-1) measurement as predictors in hemodialysis patients
}

\author{
Homare Shimohata* (D), Marina Yamashita, Kentaro Ohgi, Ryuji Tsujimoto, Hiroshi Maruyama, Mamiko Takayasu, \\ Kouichi Hirayama and Masaki Kobayashi
}

\begin{abstract}
Background: Although individuals undergoing maintenance hemodialysis are a major sarcopenic population, there are few methods to assess their skeletal muscle mass conveniently. Here, we investigated the usefulness of serum myostatin and insulin-like growth factor-1 (IGF-1) measurements for the evaluation of skeletal muscle mass.

Methods: We examined 117 patients undergoing conventional hemodialysis. The serum myostatin level and IGF-1 level were measured once and compared to clinical parameters (especially skeletal muscle mass-related factors) in hemodialysis patients.

Results: The myostatin levels were positively correlated with body cell mass, arm muscle circumference, basal metabolic rate, creatinine, creatinine phosphokinase, and albumin and negatively correlated with body fat rate, arm circumferencearm muscle circumference, age, and C-reactive protein (CRP). The IGF-1 levels were positively correlated with body cell mass, body mass index, arm muscle circumference, arm circumference-arm muscle circumference, blood urea nitrogen, creatinine, protein catabolism rate, transferrin, cholesterol, and triglyceride, and negatively with age and human atrial natriuretic polypeptide.
\end{abstract}

Conclusions: Our findings indicate that serum myostatin might be a useful biomarker for predicting muscle mass and serum IGF-1 might be a useful predictor of nutritional status in hemodialysis patients.

Keywords: Hemodialysis, IGF-1, Muscle mass, Myostatin, Serum

\section{Background}

Sarcopenia, the reduction of systemic skeletal muscle mass and muscle strength, is a change related to aging. Decreased muscle mass and strength caused by chronic inflammatory disease, a malignant tumor, or chronic kidney disease are also represented by the same concept as sarcopenia. Individuals undergoing maintenance hemodialysis are a major population among patients with sarcopenia [1].

Despite the increasing number of individuals with sarcopenia among hemodialysis patients, few methods are available for assessing a patient's skeletal muscle mass expeditiously and conveniently. Computed tomography scans, magnetic resonance imaging, and dual-energy

\footnotetext{
* Correspondence: h-shimo@tokyo-med.ac.jp

Department of Nephrology, Tokyo Medical University Ibaraki Medical Center, 3-20-1 Chuo, Ami, Inashiki, Ibaraki 300-0395, Japan
}

X-ray absorptiometry are gold-standard methods to measure muscle mass precisely, but they require the use of radiation equipment and take time to measure. A bioimpedance analysis is comparatively easy to use and generates reproducible results, but not all institutions possess the necessary bioimpedance equipment [2].

Myostatin, a member of the transforming growth factor-beta (TGF- $\beta$ ) superfamily, is known to be a negative regulator of skeletal muscle growth. Spontaneous mutation of the myostatin gene in children accounts for muscle hypertrophy [3]. Gonzalez et al. demonstrated that myostatin is an attenuator of skeletal muscle growth in adult men and contributes to muscle wasting in human immunodeficiency virus (HIV)-infected men [4]. Serum myostatin may thus seem to be a potentially useful parameter to predict an individual's skeletal muscle mass, but there are few reports about the relevance of

(C) The Author(s). 2019 Open Access This article is distributed under the terms of the Creative Commons Attribution 4.0 International License (http://creativecommons.org/licenses/by/4.0/), which permits unrestricted use, distribution, and 
serum myostatin levels and muscle mass in hemodialysis patients.

Insulin-like growth factor-1 (IGF-1) is another representative myokine. An abnormality of the growth hormone/IGF-1 axis is thought to be one of the causes of sarcopenia. Several studies have indicated that the serum IGF-1 level could be used as a predictor of nutritional status in hemodialysis patients [5-7], but there is little information about the association between the serum IGF-1 level and the muscle mass contents in dialysis patients.

In this study, we investigated the relationships among the serum myostatin level, serum IGF-1 level, and clinical parameters (especially skeletal muscle mass-related factors) in hemodialysis patients. Our findings revealed that serum myostatin is better than serum IGF-1 for the prediction of skeletal muscle mass contents.

\section{Methods}

\section{Study population}

A total of 117 hemodialysis patients who were undergoing conventional hemodialysis three times per week $(4 \mathrm{~h}$ per day) participated in our cross-sectional clinical study. Since the measurement of body composition using a bioelectrical impedance analysis was conducted in the standing position, patients who were unable to stand up were excluded. All dialysis therapy was conducted using standard high-flux dialysis membranes. The patients' characteristics are summarized in Table 1. This study was approved by the Research Ethics Committee of our hospital (IRB number 14-9), and written informed consent was obtained from all participants.

\section{Assay of serum samples}

Serum samples were collected as regular blood tests before the start of each dialysis session on the first Monday or Tuesday of April and were analyzed in our hospital blood test room using an auto-analyzer (Toshiba, Tokyo). The serum myostatin level was measured once at the same time as the above regular blood test with the use of enzyme-linked immunoassay (ELISA) kits (GDF-8/Myostatin Quantikine ELISA kit, DGDF80, R\&D Systems, Minneapolis, MN), and the serum IGF-1 level was measured by an immunoradiometric assay (IRMA) kit (IGF-1 assay "Daiichi"; TFB Co., Tokyo). Each patient's value of $K t / V$ ( $K=$ dialyzer clearance of urea, $t=$ dialysis time, $V=$ volume of distribution of urea) was estimated using Shinzato's formula [8], and the normalized protein catabolic rate (nPCR) was calculated from pre- and postdialysis blood urea nitrogen concentrations. The measurement of human atrial natriuretic polypeptide (hANP) was entrusted to an outside laboratory (LSI Medience, Tokyo).
Table 1 The characteristics of the patients $(n=117)$

\begin{tabular}{|c|c|}
\hline Age, years & $58.9 \pm 12.1$ \\
\hline Male to female & $76: 41$ \\
\hline Dialysis vintage, years & $8.67 \pm 8.1$ \\
\hline \multicolumn{2}{|l|}{ Cause of renal failure, $n$} \\
\hline CGN & $62(53 \%)$ \\
\hline DN & $39(33 \%)$ \\
\hline RPGN & $2(2 \%)$ \\
\hline PKD & $3(3 \%)$ \\
\hline Others & $11(9 \%)$ \\
\hline Alb, g/dL & $3.85 \pm 0.24$ \\
\hline BUN, mg/dL & $74.1 \pm 17.0$ \\
\hline Creatinine, mg/dL & $11.5 \pm 2.79$ \\
\hline Calcium, mg/dL & $9.16 \pm 0.96$ \\
\hline Phosphorus, mg/dL & $5.93 \pm 1.48$ \\
\hline Total cholesterol, mg/dL & $157 \pm 36$ \\
\hline $\mathrm{LDL}, \mathrm{mg} / \mathrm{dL}$ & $92.1 \pm 27.2$ \\
\hline $\mathrm{HDL}, \mathrm{mg} / \mathrm{dL}$ & $44 \pm 15$ \\
\hline Triglyceride, mg/dL & $103 \pm 72$ \\
\hline Myostatin, pg/mL & $5424 \pm 2887$ \\
\hline IGF-1, ng/mL & $156.8 \pm 70.7$ \\
\hline \multicolumn{2}{|l|}{ Drugs, $n$} \\
\hline ARB & $58(50 \%)$ \\
\hline ACEi & $3(3 \%)$ \\
\hline Calcium blocker & $71(61 \%)$ \\
\hline Vit. D & $81(69 \%)$ \\
\hline Statin & $10(9 \%)$ \\
\hline$K t / V$ & $1.36 \pm 0.24$ \\
\hline$P C R, g / k g /$ day & $0.83 \pm 0.21$ \\
\hline
\end{tabular}

$A C E i$ angiotensin converting enzyme inhibitor, $A R B$ angiotensin receptor blocker, CGN chronic glomerulonephritis, $D N$ diabetic nephropathy, $H D$ hemodialysis, IGF-1 insulin-like growth factor-1, PCR protein catabolism rate, $P K D$ polycystic kidney disease, $R P G N$ rapid progressive glomerulonephritis

\section{Body composition analysis}

The patients' body composition was measured using a segmental multi-frequency bioelectrical impedance analysis with an Inbody 3.2 device (Biospace, Tokyo). To exclude the influence of body fluid condition, the measurement of body composition was conducted just after dialysis therapy. The patients' body mass index (BMI) was calculated using body height and body weight. The basal metabolic rate (BMR), body cell mass (BCM), arm muscle circumference (AMC), arm circumference $(\mathrm{AC})$, and body fat rate were reported as additional data by the Inbody 3.2 device.

\section{Statistical analysis}

All data are given as means \pm SD. Correlations between serum myostatin, IGF-1, the results of the bioelectrical 
impedance analysis, and clinical parameters were evaluated by Spearman's rank correlation analysis. Comparison of the serum myostatin and IGF-1 levels between male and female, diabetic patients, and non-diabetic patients was performed by using the unpaired $t$ test. Multiple regression analyses were performed to explore the impact of the serum myostatin and IGF-1 level on various clinical parameters. All calculations were performed on a computer using StatView ver. 5.0J for Windows (SAS Institute, Cary, NC). Differences with $p$ values $<0.05$ were considered significant.

\section{Results}

\section{The patients' characteristics}

Table 1 summarizes the characteristics of the 117 patients. The average age was $58.9 \pm 12.1$ years, and the duration of hemodialysis was $8.67 \pm 8.1$ years. Of the enrolled patients, 76 were male and 41 were female. The causes of renal failure were chronic glomerulonephritis in 62 patients, diabetic nephropathy in 39, rapid progressive glomerulonephritis in two, polycystic kidney disease in three, and "other" in 11. The main antihypertensive drugs were a calcium blocker in 71 patients, an angiotensin receptor blocker in 58, and an angiotensin-converting enzyme in three. Vitamin D was prescribed for $64 \%$ of the patients.

The mean serum myostatin level was $5424 \pm 2887 \mathrm{pg} / \mathrm{mL}$, and the mean IGF-1 level was $156.8 \pm 70.7 \mathrm{ng} / \mathrm{mL}$. The serum myostatin level of male $(6009.1 \pm 3211.1 \mathrm{pg} / \mathrm{mL})$ and non-diabetic patients $(5868.8 \pm 3227.5 \mathrm{pg} / \mathrm{mL})$ was significantly higher than that of female $(4338.8 \pm 1727.6 \mathrm{pg} / \mathrm{mL})$ and diabetic patients $(4533.6 \pm 1766.7 \mathrm{pg} / \mathrm{mL}$ ) (gender; $P=0.003$, diabetes; $P=0.018$ ). There was no significant difference in serum IGF-1 level about having sex difference and diabetes or not. The efficacy of dialysis in the patients was sufficiently high $(K t / V 1.36 \pm 0.24)$, and the nPCR levels were slightly low $(0.83 \pm 0.21 \mathrm{~g} / \mathrm{kg} /$ day $)$ compared to general dialysis patient average levels.

\section{The relationship between serum myostatin, IGF-1, and body composition}

The patients' serum myostatin levels were significantly positively correlated with their values of body cell mass (BCM) $(r=0.487, p<0.0001)$, arm muscle circumference (AMC) $(r=0.355, p=0.001)$, and basal metabolic rate (BMR) $(r=0.441, p<0.0001)$. The patients' serum myostatin levels were significantly negatively correlated with their values of body fat rate $(r=-0.296, p=0.002)$ and arm circumference-AMC (AC-AMC) $(r=-0.214, p=0.024)$.

The patients' serum IGF-1 levels were significantly positively correlated with their BCM $(r=0.238, p=0.012)$, $\operatorname{BMI}(r=0.270, p=0.004)$, AMC $(r=0.207, p=0.029)$, and AC-AMC $(r=0.255, p=0.007)$ (Table 2$)$. The BCM is comprised of total intracellular water and protein and is
Table 2 Relationship between serum myostatin, serum IGF-1 levels, and body composition parameters

\begin{tabular}{llllll}
\hline $\begin{array}{l}\text { Bioelectrical } \\
\text { impedance } \\
\text { analysis }\end{array}$ & \multicolumn{2}{l}{ Myostatin, $\mathrm{pg} / \mathrm{mL}$} & & \multicolumn{2}{l}{ IGF-1, ng/mL } \\
\cline { 2 - 3 } & $r$ & & & $r$ & $p$ \\
\hline BMl, kg/m & 0.102 & 0.290 & & 0.270 & 0.004 \\
BMR, kcal & 0.441 & $<0.0001$ & & 0.181 & 0.058 \\
BCM, kg & 0.487 & $<0.0001$ & & 0.238 & 0.012 \\
AMC, cm & 0.355 & 0.001 & & 0.207 & 0.029 \\
AC-AMC, cm & -0.214 & 0.024 & & 0.255 & 0.007 \\
Body fat, \% & -0.296 & 0.002 & & 0.184 & 0.053 \\
\hline
\end{tabular}

$A C$ arm circumference, $A M C$ arm muscle circumference, $B C M$ body cell mass, $B M I$ body mass index, $B M R$ basal metabolic rate

thought to be a reliable muscle mass content marker. AMC measured directly by a bioelectrical impedance analyzer correlates well with the skeletal muscle mass. The BMR also depends on the content of skeletal muscle.

In contrast, the AC-AMC represents the subcutaneous fat mass of the upper arm. As our results demonstrated that the patients' serum myostatin levels were significantly positively correlated with muscle-related factors and negatively correlated with fat-related factors, it was revealed that the serum myostatin level specifically represents the extent of muscle mass. On the other hand, the serum IGF-1 level had positive correlations with both BCM and fat mass; that is, the patients' serum IGF-1 levels were positively correlated with their total body mass. These results indicate that the serum myostatin level appears to be a marker of skeletal muscle mass and that the serum IGF-1 level could be a marker of body constitution.

\section{The relationship between serum myostatin, IGF-1, and clinical laboratory parameters}

We next investigated the relationship between serum myostatin and IGF-1 levels and clinical laboratory parameters by performing a univariate analysis. The results are shown in Table 3. The serum myostatin levels correlated positively with serum creatinine $(r=0.417, p<0.0001)$, creatinine phosphokinase $(r=0.329, p=0.000)$, and albumin $(r=0.220, p=0.017)$, and negatively with age $(r=-0.326, p=0.000)$ and C-reactive protein $(r=-0.232$, $p=0.012$ ). In contrast, the serum IGF-1 levels correlated positively with blood urea nitrogen $(r=0.392, p<0.0001)$, serum creatinine $(r=0.278, p=0.002)$, the protein catabolism rate $(r=0.246, p=0.008)$, transferrin $(r=0.227$, $p=0.015)$, total cholesterol $(r=0.248, p=0.007)$, lowdensity lipoprotein $(r=0.183, p=0.048)$, and triglyceride $(r=0.307, p=0.001)$, and negatively with age $(r=-0.269$, $p=0.003)$ and hANP $(r=-0.256, p=0.005)$.

Thus, significant positive correlations to serum myostatin levels were observed in muscle-related laboratory 
Table 3 Univariate correlation of serum myostatin and IGF-1 to clinical parameters

\begin{tabular}{|c|c|c|c|c|}
\hline \multirow[t]{2}{*}{ Clinical parameters } & \multicolumn{2}{|c|}{ Myostatin, $\mathrm{pg} / \mathrm{mL}$} & \multicolumn{2}{|c|}{ IGF-1, ng/mL } \\
\hline & $r$ & $p$ & $r$ & $p$ \\
\hline Age, years & -0.326 & 0.000 & -0.269 & 0.003 \\
\hline Dialysis vintage, years & 0.072 & 0.443 & -0.168 & 0.070 \\
\hline Total protein, g/dL & -0.093 & 0.317 & 0.071 & 0.445 \\
\hline Albumin, $\mathrm{g} / \mathrm{dL}$ & 0.220 & 0.017 & 0.128 & 0.168 \\
\hline Blood urea nitrogen, mg/dL & 0.148 & 0.111 & 0.392 & $<0.000$ \\
\hline Creatinine, mg/dL & 0.417 & $<0.0001$ & 0.278 & 0.002 \\
\hline Creatinine phosphokinase, IU/L & 0.329 & 0.000 & -0.066 & 0.479 \\
\hline Protein catabolism rate, $\mathrm{g} / \mathrm{kg} /$ day & 0.068 & 0.469 & 0.246 & 0.008 \\
\hline Transferrin, mg/dL & 0.089 & 0.345 & 0.227 & 0.015 \\
\hline Total cholesterol, mg/dL & -0.036 & 0.699 & 0.248 & 0.007 \\
\hline $\mathrm{LDL}, \mathrm{mg} / \mathrm{dL}$ & -0.130 & 0.164 & 0.183 & 0.048 \\
\hline $\mathrm{HDL}, \mathrm{mg} / \mathrm{dL}$ & 0.168 & 0.070 & -0.039 & 0.674 \\
\hline Triglyceride, mg/dL & -0.018 & 0.847 & 0.307 & 0.001 \\
\hline $\mathrm{CRP}, \mathrm{mg} / \mathrm{dL}$ & -0.232 & 0.012 & 0.101 & 0.919 \\
\hline hANP, pg/mL & -0.145 & 0.119 & -0.256 & 0.005 \\
\hline$\beta 2-M G, m g / d L$ & -0.117 & 0.209 & 0.010 & 0.916 \\
\hline $\mathrm{Kt} / \mathrm{V}$ & -0.085 & 0.366 & 0.035 & 0.712 \\
\hline
\end{tabular}

CRP C-reactive protein, $h A N P$ human atrial natriuretic polypeptide, $H D L$ highdensity lipoprotein, $L D L$ low-density lipoprotein, $M G$ macroglobulin

data (serum creatinine, creatinine phosphokinase), and negative correlations to serum myostatin levels were observed in age and CRP. These results are reasonable because inflammation and aging contribute to skeletal muscle mass reduction. On the other hand, the patients' serum IGF-1 levels were correlated with nutrition-related factors such as creatinine, the protein catabolism rate, transferrin, total cholesterol, and triglyceride. Combined with the abovementioned body composition result, the serum IGF-1 level seems to be a marker of nutritional status.

\section{Multiple regression analysis of serum myostatin, IGF-1, and other factors}

We performed a multiple regression analysis to examine the relationships between serum myostatin and IGF-1 levels and other factors that had a significant correlation in the univariate analysis. The BCM was the most significant and independent positive determinant of the serum myostatin level, whereas many nutrition-related factors such as the BCM, total cholesterol, triglyceride, and the protein catabolism rate were significantly associated with serum IGF-1 (Table 4). Based on these results, we conclude that the measurement of a hemodialysis patient's serum myostatin level could be a useful tool for assessing the contents of skeletal muscle mass, and the serum IGF-1 level might become a predictor of nutritional status.
Table 4 Multiple regression analysis of serum myostatin, IGF-1 levels

\begin{tabular}{lll}
\hline Independent variable & $\beta$ & $p$ \\
\hline Myostatin, pg/mL & -0.116 & 0.205 \\
Age, years & -0.255 & 0.058 \\
Sex, male & 0.568 & $<0.0001$ \\
BCM, kg & -0.232 & 0.022 \\
Body fat, \% & 0.167 & 0.056 \\
Albumin, g/dL & -0.061 & 0.500 \\
CRP, mg/dL & & \\
IGF-1, ng/mL & -0.154 & 0.111 \\
Age, years & -0.278 & 0.042 \\
Sex, male & 0.381 & 0.022 \\
BCM, kg & 0.062 & 0.586 \\
BMl, $\mathrm{kg} / \mathrm{m}^{2}$ & 0.211 & 0.014 \\
Protein catabolism rate, g/kg/day & 0.198 & 0.037 \\
Total cholesterol, mg/dL & 0.184 & 0.069 \\
\hline Triglyceride, mg/dL &
\end{tabular}

\section{Discussion}

Myostatin is recognized as a negative regulator of skeletal muscle mass in general, and there are many reports that show a negative relationship between the serum myostatin level and muscle wasting conditions such as chronic obstructive pulmonary disease (COPD) [9], aging [10], HIV [4], and heart failure [11]. Saremi et al. showed that resistance training for 8 weeks led to a significant decrease in the serum level of myostatin [12]. In the field of basic research, Zhang et al. showed that the administration of a myostatin inhibitor suppressed muscle atrophy in mice with chronic kidney disease [13].

Our present analyses demonstrated that the patients' serum myostatin levels were positively correlated with muscle-related factors such as the BCM, AMC, BMR, and serum creatinine level. These results are opposite those described in previous reports. The reason why we obtained opposite results is uncertain. According to the yin and yang theory of Mak and Rotwein [14], myostatin plays inhibitory roles in the situation of skeletal muscle increase. This means the expression of myostatin increases in the skeletal muscle growth condition, whereas increased myostatin might also accumulate in the serum of patients with renal dysfunction. Previously, Yamada et al. showed serum myostatin levels were significantly and positively associated with lean body mass and serum creatinine levels in patients undergoing peritoneal dialysis [15]. These results support our assumption that serum myostatin increase with muscle mass in patient having renal dysfunction. Furthermore, Han et al. demonstrated that the time-averaged concentration of serum myostatin 
was positively related to the BMI and negatively related to grip strength but not to muscle mass [16]. Willoughby demonstrated that 12-week resistance training increased not only the subjects' total body mass, fat-free mass, strength, and thigh volume and mass but also their skeletal muscle myostatin mRNA, skeletal muscle myostatin content, and serum myostatin content [17]. In that report, Willoughby explains that the observed increase in serum myostatin that occurred in response to resistance training was likely inhibited by concomitant increases in serum follistatin-like-related gene along with the concomitant downregulation of the activin $2 \mathrm{~b}$ receptor, and he suggested that this is the reason why resistance training is associated with increases in myostatin mRNA, skeletal muscle mass, and serum myostatin.

In our study, the serum follistatin-like-related gene was not measured, so it is unclear whether that level was high or low. However, in light of the findings reported by Yamada et al., Han et al., and Willoughby, it seems that the existence of a positive relationship between skeletal muscle mass and the serum myostatin level is possible.

The decreases of growth hormone and IGF-1 with aging have been implicated in the progressive decline of lean body mass [18], and Caregaro et al. demonstrated that in patients with eating disorders, serum IGF-1 was correlated with the BMI, body fat, mid-arm muscle circumference, and muscle mass, whereas it was not correlated with serum protein [19]. These results are similar to our present findings, and we agree with their conclusion that IGF-1 appears to be a reliable biochemical marker of malnutrition. In addition, in elderly women, 12 weeks of muscle strength training (but not aerobic training) increased serum IGF-1 levels without a change in the cortisol level [20], and another study demonstrated that 8 weeks of resistance training increased the total IGF-1 concentration and decreased the insulin-like growth factor-binding protein 1 (IGFBP-1) concentration [21].

In light of these previous reports, we speculated that the serum IGF-1 level could be a predictor of skeletal muscle mass, similar to the serum myostatin level. However, our results indicated that the serum IGF-1 level represented the patients' general nutritional status and not the skeletal muscle mass only. Especially, the serum IGF-1 levels correlated positively with total cholesterol, low-density lipoprotein, and triglyceride. Malik et al. showed that isolated hypercholesterolemia subjects and mixed hyperlipidemia subjects (high cholesterol and high triglyceride) had a lower IGF-1 in general population [22]. Since these results are opposite to our results, we consider that the positive association between serum IGF-1 and lipid profile was limited to dialysis patients. Several reports have described IGF-1 as a predictor of malnutrition in hemodialysis patients [5-7], but there are few reports that show the relationship between the serum IGF-1 level and skeletal muscle mass in hemodialysis patients. Rymarz et al. recently demonstrated that the body cell mass (measured by bioimpedance spectroscopy), handgrip strength, and serum creatinine were positively correlated with IGF-1 [23]. Since these findings are identical to our present results, it appears that positive correlations might exist between IGF-1 and muscle-related factors (such as body cell mass) and serum creatinine. However, our multiple regression analysis revealed that serum myostatin but not serum IGF-1 has a strong relationship with muscle mass contents.

Our study has several limitations. First, the study population was small because the study was conducted at a single dialysis center. Our patients may thus not represent general dialysis populations. However, since we sought to reveal the relationship between myokines (myostatin and IGF-1) and clinical parameters (especially muscle mass-related factors) and to investigate the usage of these myokines for the prediction of muscle mass, we were able to achieve our goals in this study. We hope that our results are proven by future large population studies.

Second, since our study design was cross-sectional, it is uncertain whether changes in clinical parameters are reflected by changes in serum myostatin or IGF-1 levels. We are now planning to conduct longitudinal research to investigate the changes in serum myostatin and IGF-1 levels before and after resistance exercise during hemodialysis treatment.

\section{Conclusions}

In conclusion, our findings indicate that serum myostatin might be a useful biomarker for predicting muscle mass contents in hemodialysis patients, and serum IGF-1 might be a useful predictor of nutritional status including muscle mass in hemodialysis patients. Further studies of larger populations and longitudinal research are needed to confirm these results.

\footnotetext{
Abbreviations

AC: Arm circumference; ACEi: Angiotensin-converting enzyme inhibitor; AMC: Arm muscle circumference; ARB: Angiotensin receptor blocker; BCM: Body cell mass; BMl: Body mass index; BMR: Basal metabolic rate; CGN: Chronic glomerulonephritis; COPD: Chronic obstructive pulmonary disease; DN: Diabetic nephropathy; ELISA: Enzyme-linked immunoassay; hANP: Human atrial natriuretic polypeptide; HD: Hemodialysis; HDL: Highdensity lipoprotein; HIV: Human immunodeficiency virus; IGF-1: Insulin-like growth factor-1; IGFBP-1: Insulin-like growth factor-binding protein 1; LDL: Low-density lipoprotein; MG: Macroglobulin; nPCR: Normalized protein catabolic rate; PKD: Polycystic kidney disease; RPGN: Rapid progressive glomerulonephritis; TGF- $\beta$ : Transforming growth factor-beta

Acknowledgements

The authors thank all investigators and contributors of our study.

Funding

The author declares that there is no funding about this study.
} 


\section{Availability of data and materials}

The datasets analyzed during the present study are available from the corresponding author on reasonable request.

\section{Authors' contributions}

HS designed and performed the research and wrote the paper. MY, KO, RT, $H M$, and MT performed the research. HS, KH, and MK analyzed the data. All authors read and approved the final version of the manuscript.

\section{Ethics approval and consent to participate}

This study was approved by the Research Ethics Committee of Tokyo Medical University Ibaraki Medical Center (IRB number 14-9), and written informed consent was obtained from patients.

\section{Consent for publication}

Not applicable.

\section{Competing interests}

The authors declare that they have no competing interests.

\section{Publisher's Note}

Springer Nature remains neutral with regard to jurisdictional claims in published maps and institutional affiliations.

Received: 18 January 2019 Accepted: 13 May 2019

Published online: 22 May 2019

\section{References}

1. Woodrow G, Oldroyd B, Turney JH, Tompkins L, Brownjohn AM, Smith MA Whole body and regional body composition in patients with chronic renal failure. Nephrol Dial Transplant. 1996;11:1613-8.

2. Cruz-Jentoft AJ, Baeyens JP, Bauer JM, et al. Sarcopenia: European consensus on definition and diagnosis: report of the European Working Group of Sarcopenia in Older People. Age Ageing. 2010;39:412-23.

3. Schuelke M, Wagner KR, Stolz LE, et al. Myostatin mutation of human muscle mass. N Engl J Med. 2004:350:2682-8.

4. Gonzalez-Cadavid NF, Taylor WE, Yarasheski K, et al. Organization of the human myostatin gene and expression in healthy men and HIV-infected men with muscle wasting. Proc Natl Acad Sci U S A. 1998;95:14938-43.

5. Jacob V, Le Carpentier JE, Salzano S, et al. IGF-1, a marker of undernutrition in hemodialysis patients. Am J Clin Nutr. 1990;52:39-44.

6. Sanaka T, Shinobe M, Ando M, Hizuka N, Kawaguchi H, Nihei H. IGF-1 as an early indicator of malnutrition in patients with end-stage renal disease. Nephron. 1994;67:73-81

7. Qureshi AR, Alvestrand A, Danielsson A, et al. Factors predicting malnutrition in hemodialysis patients: a cross-sectional study. Kidney Int. 1998:53:773-82.

8. Shinzato T, Nakai S, Fujita $Y$, et al. Determination of $\mathrm{Kt} / \mathrm{V}$ and protein catabolic rate using pre- and postdialysis blood urea nitrogen concentrations. Nephron. 1994;67:280-90.

9. Ju CR, Chen RC. Serum myostatin levels and skeletal muscle wasting in chronic obstructive pulmonary disease. Respir Med. 2012;106:102-8.

10. Yarasheski KE, Bhasin S, Bhasin S, Sinha-Hikim I, Pak-Loduca J, GonzalezCadavid NF. Serum myostatin-immunoreactive protein is increased in 60-92 year old women and men with muscle wasting. J Nutr Health Aging. 2002;6:343-8.

11. George I, Bish LT, Kamalakkannan G, et al. Myostatin activation in patients with advanced heart failure and after mechanical unloading Eur J Heart Fail. 2010;12:444-53.

12. Saremi A, Gharakhanloo R, Sharghi S, Gharaati MR, Larijani B, Omidfar K. Effects of oral creatine and resistance training on serum myostatin and GASP-1. Mol Cell Endocrinol. 2010;317:25-30.

13. Zhang L, Rajan $V$, Lin $E$, et al. Pharmacological inhibition of myostatin suppresses systemic inflammation and muscle atrophy in mice with chronic kidney disease. FASEB J. 2011;25:1653-63.

14. Mak RH, Rotwein P. Myostatin and insulin-like growth factors in uremic sarcopenia: the yin and yang in muscle mass regulation. Kidney Int. 2006;70(3):410-2.

15. Yamada $\mathrm{S}, \mathrm{T}$ suruya $\mathrm{K}$, Toshida $\mathrm{H}$, et al. Factors associated with the serum myostatin level in patients undergoing peritoneal dialysis: potential effects of skeletal muscle mass and vitamin D receptor activator use. Calcif Tissue Int. 2016;99(1):13-22.

16. Han DS, Chen YM, Lin SY, et al. Serum myostatin levels and grip strength in normal subjects and patients on maintenance haemodialysis. Clin Endocrinol. 2011;75:857-63.

17. Willoughby DS. Effects of heavy resistance training on myostatin mRNA and protein expression. Med Sci Sports Exerc. 2004;36:574-82.

18. Rudman D. Growth hormone, body composition, and aging. J Am Geriatr Soc. 1985;33:800-7.

19. Caregaro L, Favaro A, Santonastaso $P$, et al. Insulin-like growth factor 1 (IGF-1), a nutritional marker in patients with eating disorders. Clin Nutr. 2001;20:251-7.

20. Vale RG, de Oliveira RD, Pernambuco CS, de Meneses YP, Novaes Jda S, de Andrade Abe F. Effects of muscle strength and aerobic training on basal serum levels of IGF-1 and cortisol in elderly women. Arch Gerontol Geriatr. 2009:49:343-7.

21. Gregory SM, Spiering BA, Alemany JA, et al. Exercise-induced insulin-like growth factor I system concentrations after training in women. Med Sci Sports Exerc. 2013;45:420-8.

22. Malik J, Stulc T, Wichterle D, et al. Hyperlipidemia is associated with altered levels of insulin-like growth factor-1. Physiol Res. 2008:57:919-25.

23. Rymarz A, Bartoszewicz Z, Szamotulska K, Niemczyk S. The associations between body cell mass and nutritional and inflammatory markers in patients with chronic kidney disease and in subjects without kidney disease. J Ren Nutr. 2016;26:87-92.

\section{Ready to submit your research? Choose BMC and benefit from:}

- fast, convenient online submission

- thorough peer review by experienced researchers in your field

- rapid publication on acceptance

- support for research data, including large and complex data types

- gold Open Access which fosters wider collaboration and increased citations

- maximum visibility for your research: over $100 \mathrm{M}$ website views per year

At BMC, research is always in progress.

Learn more biomedcentral.com/submissions 